\title{
Gabapentin for the hemodynamic response to intubation: systematic review and meta-analysis
}

\section{La gabapentine pour atténuer la réponse hémodynamique à l'intubation: compte rendu méthodique et méta-analyse}

\author{
Brett Doleman, MBBS • Matthew Sherwin, BMBS • Jonathan N. Lund, DM • \\ John P. Williams, PhD
}

Received: 1 January 2016/Revised: 27 March 2016/Accepted: 6 May 2016/Published online: 20 May 2016

(C) Canadian Anesthesiologists' Society 2016

\begin{abstract}
Purpose Endotracheal intubation is the gold standard for securing the airway before surgery. Nevertheless, this procedure can produce an activation of the sympathetic nervous system and result in a hemodynamic response which, in high-risk patients, may lead to cardiovascular instability and myocardial ischemia. The aim of this review was to evaluate whether gabapentin can attenuate this response and whether such an attenuation could translate into reduced myocardial ischemia and mortality.

Source We searched MEDLINE ${ }^{\circledR}, E M B A S E^{T M}$, CINAHL, $A M E D$, and unpublished clinical trial databases for randomized-controlled trials that compared gabapentin with control, fentanyl, clonidine, or beta blockers for attenuating the hemodynamic response to intubation. Primary outcomes were mortality, myocardial infarction, and myocardial ischemia. Secondary outcomes were hemodynamic changes following intubation.

Principal findings We included 29 randomized trials with only two studies at low risk of bias. No data were provided for the primary outcomes and no studies included high-risk patients. The use of gabapentin resulted in attenuation in the rise in mean arterial blood pressure [mean difference (MD), $-12 \mathrm{mmHg}$; 95\% confidence interval (CI), -17 to $-8]$ and heart rate $\left(\mathrm{MD},-8\right.$ beats $\cdot \mathrm{min}^{-1} ; 95 \% \mathrm{CI},-11$ to

-5) one minute after intubation. Gabapentin also reduced the risk of hypertension or tachycardia requiring treatment (risk ratio, 0.15; 95\% CI, 0.05 to 0.48). Data were limited
\end{abstract}

B. Doleman, MBBS $(\bowtie) \cdot$ M. Sherwin, BMBS .

J. N. Lund, DM · J. P. Williams, PhD

Division of Medical Sciences and Graduate Entry Medicine,

University of Nottingham, Royal Derby Hospital, Uttoxeter New

Rd, Derby DE22 3DT, UK

e-mail: dr.doleman@gmail.com on adverse hemodynamic events such as bradycardia and hypotension.

Conclusion It remains unknown whether gabapentin improves clinically relevant outcomes such as death and myocardial infarction since studies failed to report on these. Nevertheless, gabapentin attenuated increases in heart rate and blood pressure following intubation when compared with the control group. Even so, the studies included in this review were at potential risk of bias. Moreover, they did not include high-risk patients or report adverse hemodynamic outcomes. Future studies are required to address these limitations.

\section{Résumé}

Objectif L'intubation endotrachéale constitue l'étalon or de la prise en charge des voies aériennes avant une chirurgie. Toutefois, cette intervention peut entraîner une activation du système nerveux sympathique et provoquer une réponse hémodynamique qui, chez les patients courant un risque élevé, pourrait mener à une instabilité cardiovasculaire et une ischémie myocardique. L'objectif de ce compte rendu était d'examiner si la gabapentine pouvait atténuer cette réponse et si une telle atténuation pouvait se traduire en une réduction de l'ischémie myocardique et de la mortalité.

Source Nous avons effectué des recherches dans les bases de données MEDLINE ${ }^{\circledR}, E M B A S E^{T M}$, CINAHL, AMED, ainsi que dans les bases de données d'études cliniques non publiées afin d'en extraire les études randomisées contrôlées comparant la capacité de la gabapentine par rapport à un groupe témoin, au fentanyl, à la clonidine ou à des bêta-bloquants, à atténuer la réponse hémodynamique à l'intubation. La mortalité, l'infarctus du myocarde et l'ischémie myocardique étaient les 
principaux critères d'évaluation. Les critères d'évaluation secondaires étaient les changements hémodynamiques suite à l'intubation.

Constatations principales Nous avons inclus 29 études randomisées, dont deux seulement affichaient un risque faible de biais. Aucune donnée n'était fournie concernant les critères d'évaluation principaux et aucune étude n'incluait de patients à risque élevé. L'utilisation de la gabapentine a entraîné une atténuation de l'augmentation de la tension artérielle moyenne [différence moyenne (DM), $-12 \mathrm{mmHg}$; intervalle de confiance (IC) $95 \%,-17$ à -81 et de la fréquence cardiaque (DM, -8 battements. $\min ^{-1}$; IC $95 \%,-11$ à -5) une minute après l'intubation. La gabapentine a également réduit le risque d'hypertension ou de tachycardie nécessitant un traitement (risque relatif, 0,15; IC $95 \%, 0,05$ à 0,48). Les données concernant les complications hémodynamiques telles que la bradycardie et l'hypotension étaient limitées.

Conclusion Nous ne savons pas si la gabapentine améliore des résultats pertinents d'un point de vue clinique tels que le décès ou l'infarctus du myocarde, étant donné que les études examinées ne faisaient pas mention de ces données. Toutefois, la gabapentine a atténué les augmentations de fréquence cardiaque et de tension artérielle après l'intubation comparativement au groupe témoin. Ceci étant dit, les études incluses dans ce compte rendu couraient un risque potentiel de biais. De plus, elles n'incluaient pas de patients à risque élevé ni ne rapportaient de complications hémodynamiques. Des études supplémentaires sont nécessaires pour pallier ces limitations.

Endotracheal intubation is the gold standard for securing the airway before surgery. Nevertheless, this procedure may cause activation of the sympathetic nervous system and release of catecholamines, resulting in a hemodynamic response that precipitates an increase in heart rate (HR) and blood pressure. This response does not cause problems in most patients; however, in high-risk patient groups, such as those with preexisting cardiovascular disease, such responses may increase the risk of myocardial ischemia, myocardial infarction, and mortality. ${ }^{1}$ As the number of elderly patients undergoing surgery increases, adverse cardiovascular responses to endotracheal intubation may therefore present an increasing problem in the perioperative period. Many agents have been used to attenuate this response, but few studies report clinically relevant outcomes such as morbidity or mortality. ${ }^{2}$

Increases in hemodynamic and sympathetic responses around the perioperative period may increase myocardial demand and ensuing adverse cardiac outcomes. ${ }^{3}$ Triggers for these reactions include intubation, extubation, surgery, and pain. The likelihood of such adverse effects led to the conduct of randomized-controlled trials evaluating cardioprotective agents, such as beta blockers and clonidine, in reducing perioperative myocardial events. The Perioperative Ischemic Evaluation (POISE) ${ }^{4}$ study found that perioperative metoprolol reduced myocardial infarction; however, the study did not focus specifically on the specified time period of intubation and there was an increase in overall mortality and stroke. Clonidine has also shown initial promise, ${ }^{5}$ although results of the recent POISE 2 study showed no reduction in cardiac events or mortality and an increase in clinically significant hypotension and non-fatal cardiac arrest. ${ }^{6}$ Therefore, the search for alternative agents that do not produce such adverse effects is a clinically important issue for high-risk patients undergoing surgery.

Gabapentin has proven efficacy in reducing postoperative pain, lowering opioid consumption, and reducing postoperative nausea and vomiting. ${ }^{7}$ A recent meta-analysis has also identified the benefits of gabapentin with regard to preoperative anxiety and chronic pain at the expense of an increase in sedation. ${ }^{8}$ Over the last decade, randomized-controlled trials have been published indicating that gabapentin may also be useful in attenuating the hemodynamic response to intubation. ${ }^{9}$ Nevertheless, these studies included a small number of participants and were not conducted in multiple clinical populations. Moreover, it is as yet unknown how gabapentin compares with other agents and whether such reductions in hemodynamic variables could translate into reductions in clinically relevant postoperative outcomes.

Due to the disappointing results from clinical trials of clonidine and beta blockers in reducing perioperative myocardial events, ${ }^{10}$ this review aimed to evaluate whether gabapentin can attenuate the hemodynamic response to intubation and whether this can translate into reductions in myocardial ischemia and myocardial infarction and ultimately reduce postoperative mortality.

\section{Methods}

\section{Search strategy}

In conducting this review, we adhered to the standards of reporting in the Preferred Reporting Items for Systematic Reviews and Meta-Analyses (PRISMA) checklist. ${ }^{11} \mathrm{We}$ prospectively registered the review on the PROSPERO website using the registration number CRD42015027012. A deviation from the original protocol was the addition of 
intravenous fentanyl as a comparison due to its use as the standard agent at induction of anesthesia. We searched the following databases: MEDLINE ${ }^{\circledR}$ (1946-September 2015) (Appendix), EMBASE ${ }^{\mathrm{TM}}$ (1974- September 2015), CINAHL (1981- September 2015), AMED (1985September 2015), and CENTRAL (until September 2015). We searched for studies using the keywords in the title and abstract, gabapentin, Neurontin, and intubation. The MeSH terms intubation and intratracheal were exploded and combined with the above terms. We also searched for unpublished studies from Clinicaltrials.gov, the ISRCTN registry, and the WHO international clinical trials registry. Furthermore, we searched the reference lists of the identified studies and used Google Scholar to identify studies that had cited those included. We contacted the authors if further information was required.

\section{Inclusion criteria}

We included randomized-controlled trials that compared gabapentin with either placebo or no treatment in patients undergoing endotracheal intubation before surgery. We also included studies comparing the administration of gabapentin with fentanyl, clonidine, or beta blockers. We included adult patients only ( $>15 \mathrm{yr}$ old) undergoing any type of surgery. There were no restrictions based on publication status or language. When necessary, we used Google Translate to translate non-English-language papers. Two study authors (B.D. and M.S.) independently evaluated the identified studies against the inclusion criteria, and agreement was reached by consensus.

\section{Outcomes}

The primary outcomes were mortality, myocardial ischemia, and myocardial infarction. We defined mortality as early ( $<48 \mathrm{hr}$ ) and late (30 days). If studies reported more than one time point, we included the earliest time in the analysis. Myocardial ischemia was defined as ST segment depression from continuous electrocardiogram (ECG) recordings. Myocardial infarction was defined as two of the following three criteria: chest pain, ECG ischemic changes, and/or $>25 \%$ rise in high-sensitivity troponin measurements. Secondary outcomes included HR, mean arterial blood pressure, systolic blood pressure (SBP), and diastolic blood pressure (DBP) measured at one, five, and ten minutes after intubation. We also measured the following outcomes: arrhythmias, plasma catecholamine concentrations, hypotension (requiring treatment), bradycardia (requiring treatment), and tachycardia or hypertension (requiring treatment).
Data extraction and risk of bias

Two study authors (B.D. and M.S.) extracted the following information onto an electronic database: study name, year of publication, mean age of participants, percentage of female participants, sample size, intervention, comparator, country, perioperative medication, induction agents, maintenance agents, laryngoscope and endotracheal tube used, participant population, type of surgery, and duration of intubation. The same two authors assessed risk of bias using the Cochrane tool for assessing risk of bias, ${ }^{12}$ and agreement was reached by consensus. We assessed the following domains: randomization, allocation concealment, blinding, attrition bias, selective outcome reporting, and other sources of bias. These domains were assessed as low risk, unclear risk, and high risk and presented in a risk of bias table.

Statistical analysis

We present continuous outcomes using mean difference (MD) and dichotomous outcomes using risk ratios (RR). The precision of outcomes is presented with $95 \%$ confidence intervals $(95 \% \mathrm{CI})$. We regarded a $10 \%$ relative risk difference in dichotomous outcomes, a 10 $\mathrm{mmHg} \mathrm{MD}$ in blood pressure, and 5 beats $\min ^{-1} \mathrm{MD}$ in $\mathrm{HR}$ as clinically significant. We were unaware of any data directly linking changes in hemodynamic variables and risk of myocardial events, and therefore, these values for clinical significance were not empirically derived. Where data were not presented, authors were contacted to provide further information. If no response was received, the results were extracted from published graphs. If standard deviations were not published, we estimated these from other studies in the meta-analysis. ${ }^{13}$ We used the Grading of Recommendations, Assessment, Development and Evaluations (GRADE) Working Group criteria to assess the quality of evidence for each outcome. ${ }^{14}$ The evidence is downgraded owing to any concerns regarding the indirectness of evidence, lack of precision in effect estimates, potential publication bias, unexplained heterogeneity, and risk of bias in results. This is a qualitative downgrading from high quality to moderate, low, or very low quality dependent on the concerns cited above. We made no statistical adjustment of results.

Data were aggregated using a random effects model due to substantial clinical heterogeneity in the gabapentin dose and baseline hemodynamic variables of the participants. Statistical heterogeneity is presented using the $\mathrm{I}^{2}$ statistic with a corresponding $P$ value derived from the Chi square statistic. We regarded $\mathrm{I}^{2}$ of $>50 \%$ or $P<0.10$ as evidence of statistical heterogeneity. When more than ten studies were included in the meta-analysis, we assessed small 
study effects, including possible publication bias, using Egger's linear regression test. ${ }^{15}$ We regarded a one-tailed $P$ $<0.10$ as evidence of small study effects.

Investigation of heterogeneity was conducted using a method of moments random-effects meta-regression. ${ }^{16}$ Covariates included the dose of gabapentin and baseline hemodynamic variables of the participants. We calculated the baseline hemodynamic measurements by taking the mean measurement from the gabapentin and control groups recorded before induction of anesthesia (where reported). We assessed residuals for normality, linearity, and heteroscedasticity. We used Cook's distance to assess the model for influential cases and the variance inflation factor for evidence of multicollinearity. We present results as the $\mathrm{R}^{2}$ analogue with a corresponding $P$ value for the model (significance level $P<0.10$ ). We conducted sensitivity analysis by including studies at low risk of bias (defined as low risk for randomization, allocation concealment, blinding and attrition bias, and no high-risk domains), excluding studies with estimated standard deviations, and using "Remove-One" analysis.

We conducted trial sequential analysis for each outcome when gabapentin was compared with control. This analysis allows for control of type I errors, which may occur early on in the systematic review process (false discovery rate). This is analogous to the problems of multiple statistical testing in primary studies. Monitoring boundaries can be constructed so that, early in the evidence accrual, a greater $\mathrm{Z}$ score is required to reach statistical significance. As each study is published, a cumulative $\mathrm{Z}$ score is calculated, and if this crosses the monitoring boundary, it can be assumed that statistical significance is adjusted for multiple comparisons. We constructed O'Brien-Fleming monitoring boundaries for benefit assuming an alpha level of 0.05 and a 1-beta of 0.80 . In addition, we calculated the required number of included participants to provide a definitive result (information size) in order to reduce type II errors. ${ }^{17}$ This part of the analysis is analogous to a sample size calculation in primary research studies, which also makes allowances for the statistical heterogeneity of results and the uncertainty that surrounds these. We used previously stated clinically relevant MDs for continuous outcomes (10 $\mathrm{mmHg}$ or 5 beats $\mathrm{min}^{-1}$ ) and $20 \%$ or $50 \%$ relative risk reductions for dichotomous outcomes. We used the included studies in each analysis to estimate the diversity $\left(\mathrm{D}^{2}\right.$ with a calculated heterogeneity correction) and variance. We conducted sensitivity analyses around these estimates. All analyses were performed using Review Manager 5.3, ${ }^{18}$ Comprehensive Meta-Analysis V3.3, ${ }^{19}$ and Trial Sequential Analysis 0.9 beta software from the Copenhagen Trial Unit (http://www.ctu.dk/tsa).

\section{Results}

\section{Description of included studies}

We screened 95 studies identified from searching electronic databases and handsearching reference lists (Fig. 1) and included 29 studies in the meta-analysis (Table). ${ }^{20-48}$ All the included studies enrolled American Society of Anesthesiologists physical status I or II patients with no preexisting cardiac risk factors, and there were no studies involving patients at high risk for adverse cardiac
Fig. 1 PRISMA flowchart for included studies

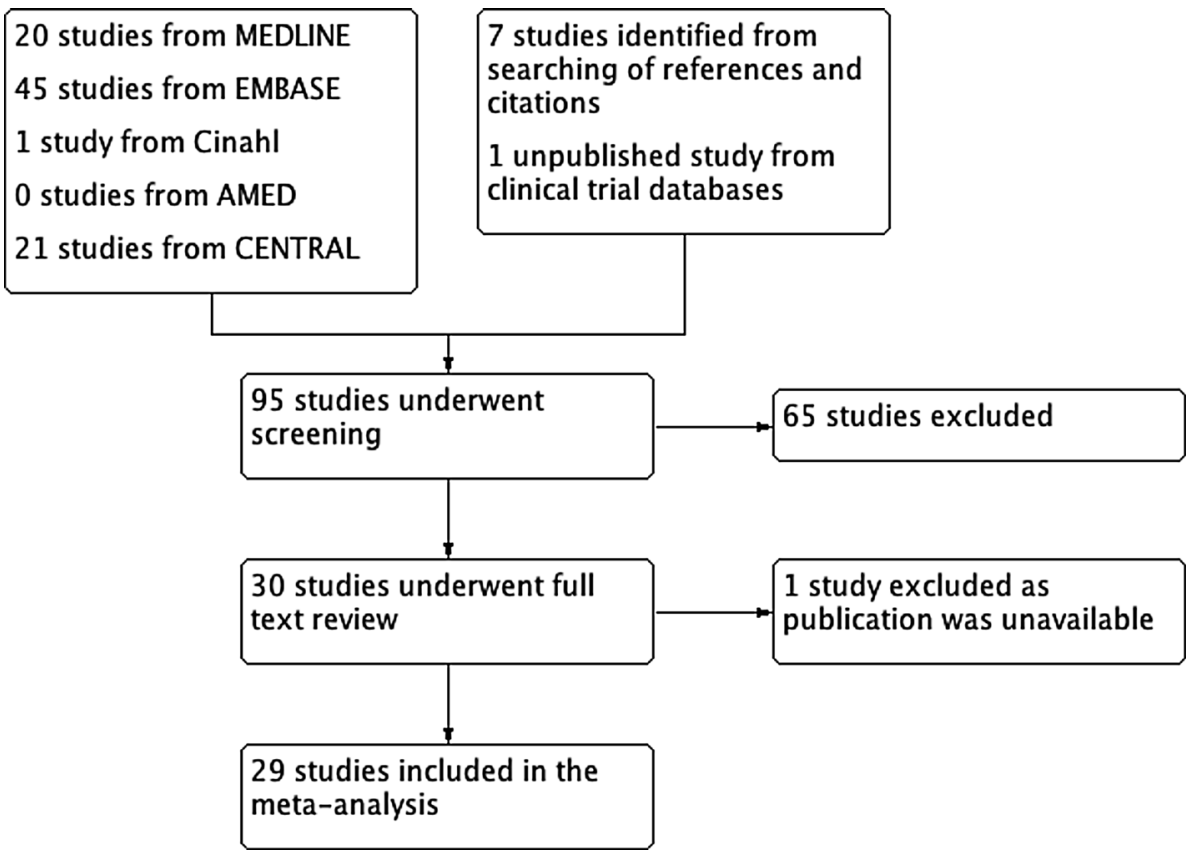




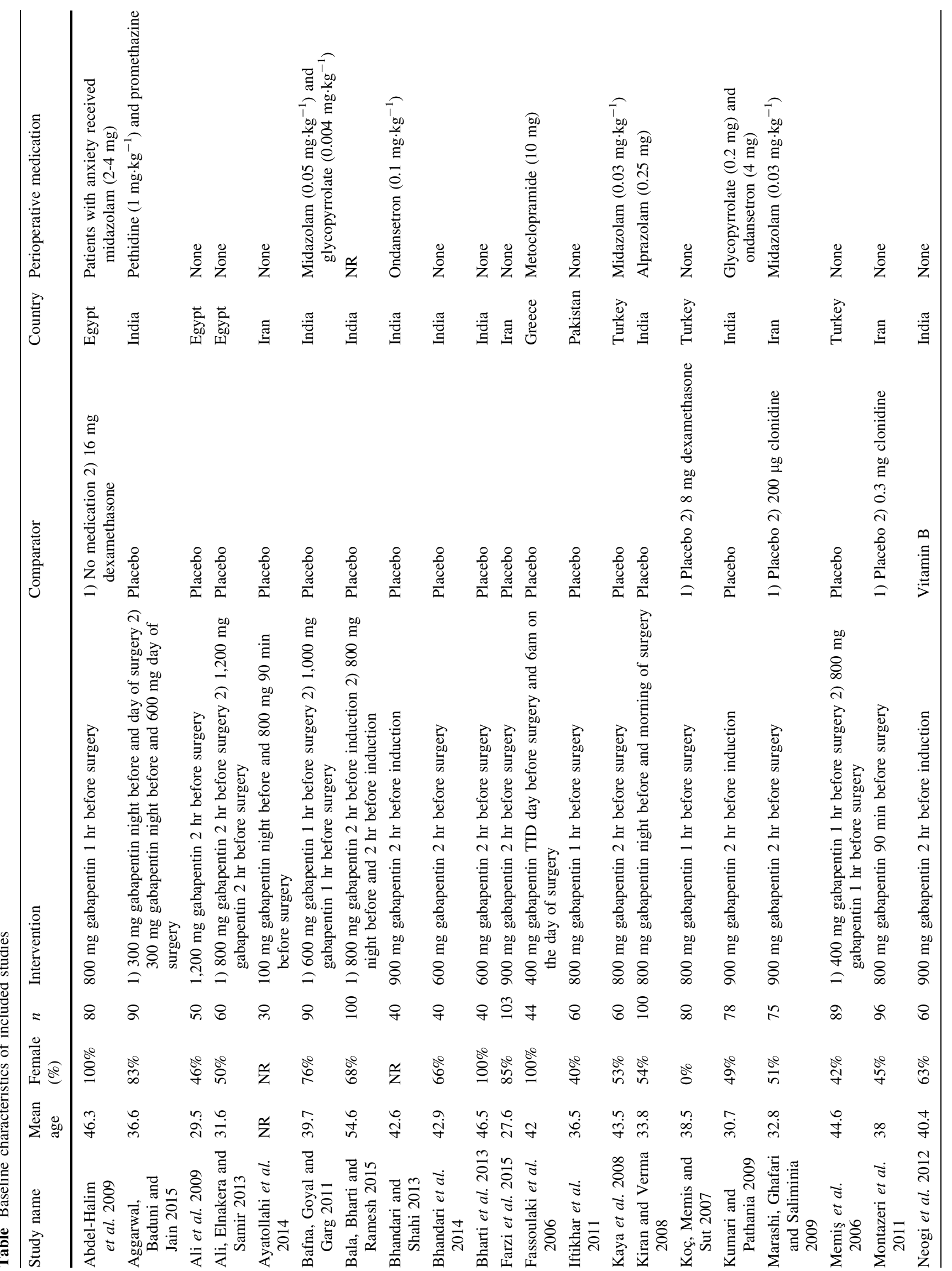




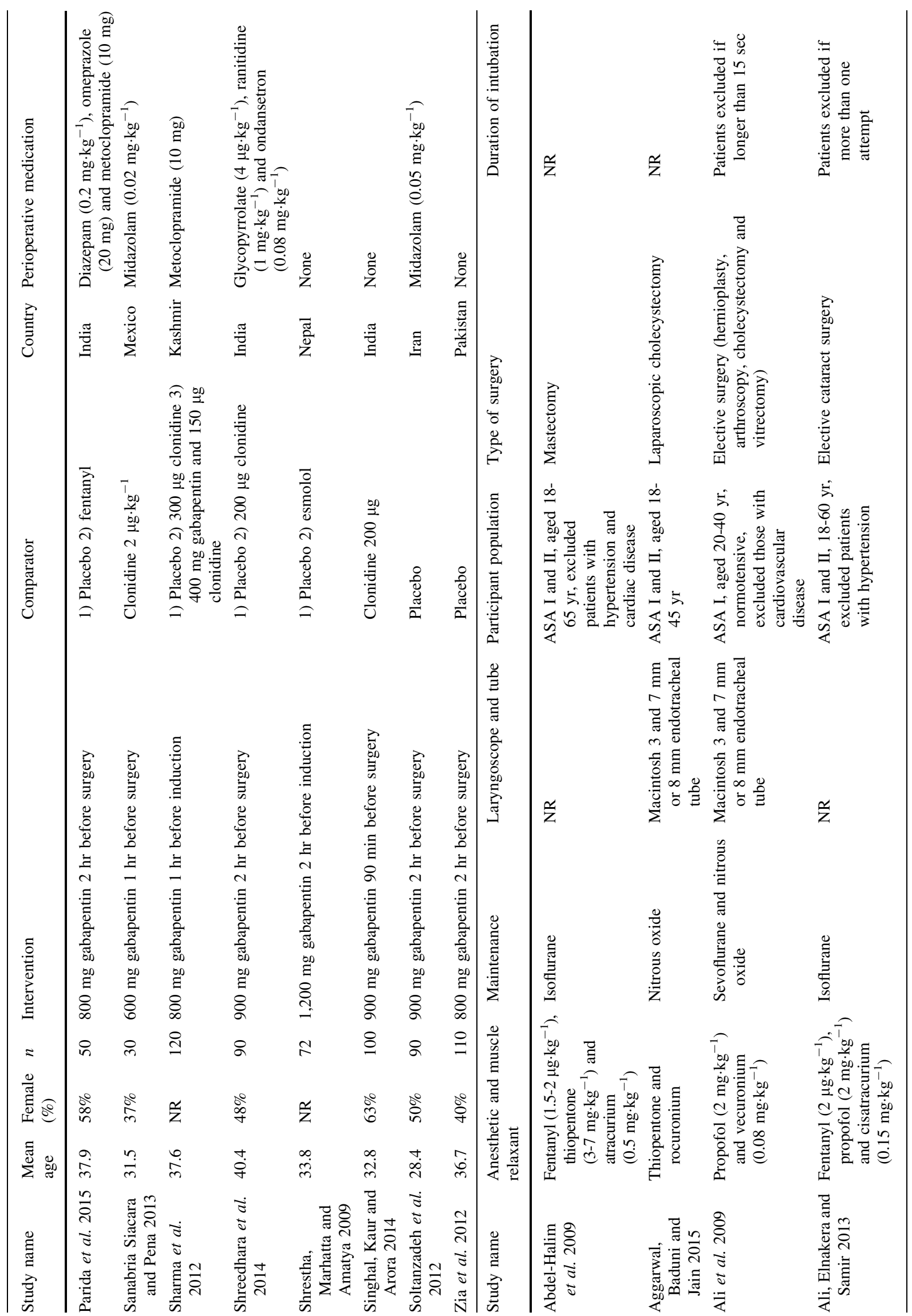




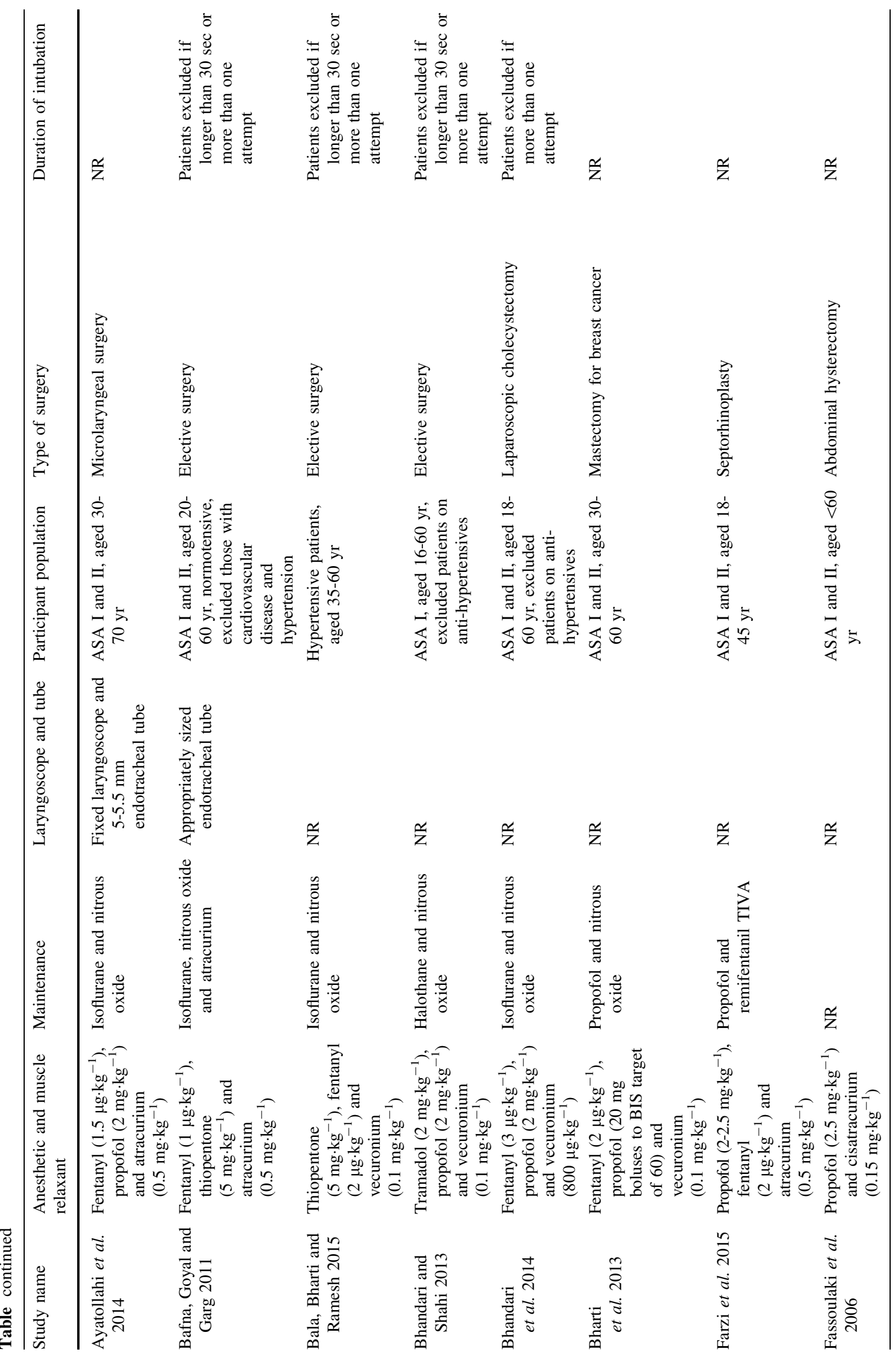




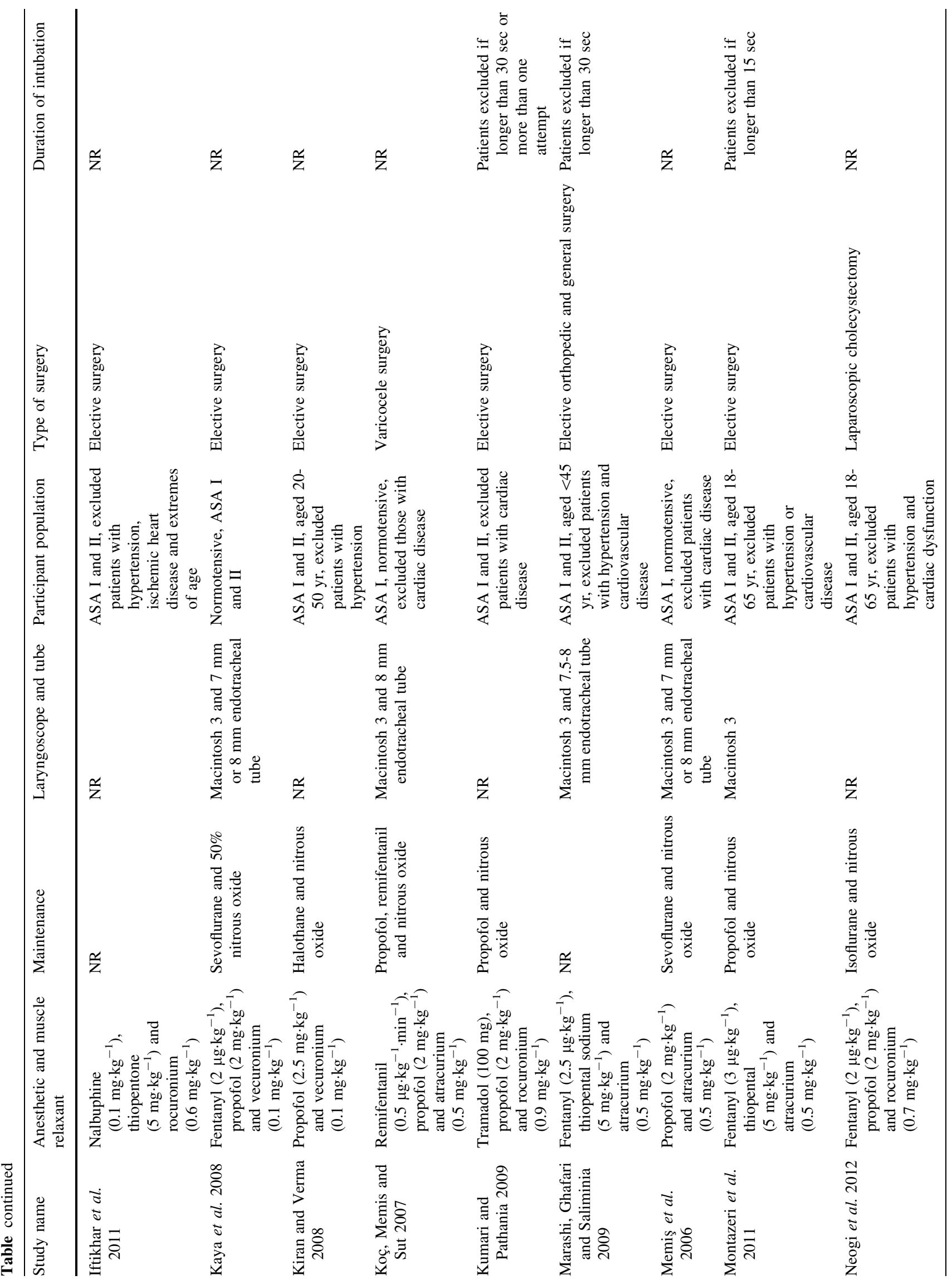




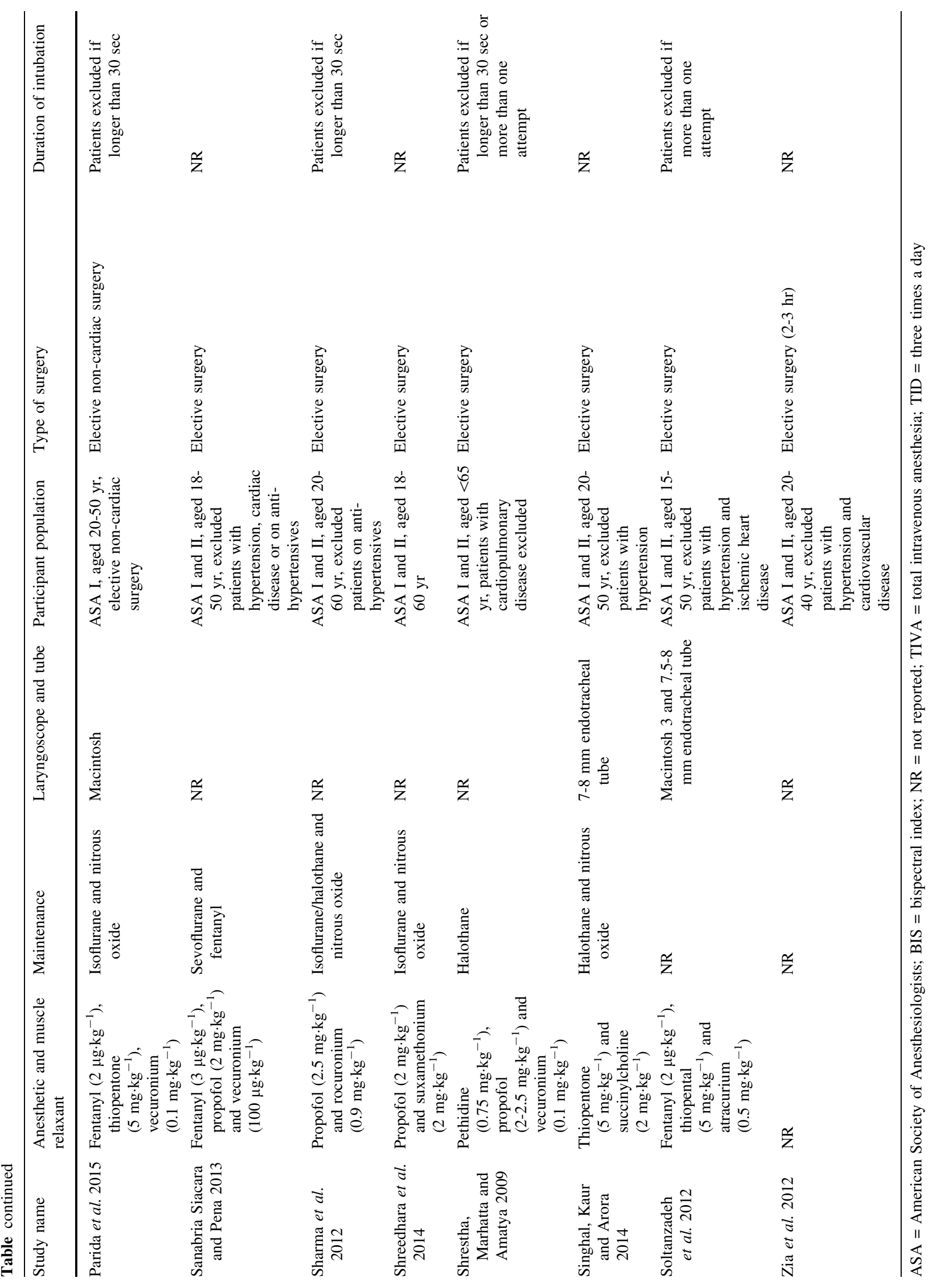


outcomes. One study included patients with hypertensive disease, ${ }^{26}$ and one study used invasive blood pressure monitoring to record hemodynamic variables. ${ }^{22}$ Only one study provided details of the equipment used to measure noninvasive blood pressure. ${ }^{33}$ There was clinical heterogeneity in the doses of gabapentin used, with doses ranging from 300-1,200 mg. Most studies administered gabapentin from one to two hours before surgery. In terms of risk of bias assessments, allocation concealment was rarely adequately reported. The risk of bias for each included study is presented in Fig. 2. Only two studies were at low risk of bias. ${ }^{35,41}$ None of the hemodynamic values measured declined below post-induction values following intubation.

\section{Gabapentin vs control}

\section{Primary outcomes}

None of the included studies reported mortality or myocardial infarction or measured them as outcomes. Nine studies $21,22,25,26,33,35,38,39,41$ reported myocardial ischemia. There were no events in either group in any of the included studies. All studies reporting myocardial ischemia derived data from ST changes on ECG recordings during the intraoperative period.

\section{Secondary outcomes}

Mean arterial blood pressure Gabapentin attenuated the rise in mean arterial pressure (MAP) at one minute when compared with the control group (MD, $-12 \mathrm{mmHg}$; $95 \%$ CI, -17 to -8 ; low quality) (Fig. 3). At five minutes, the analysis included 21 studies $^{21-24,26,28-30,32-39,41,43-45,47}$ with 1,350 participants where the aggregated effect estimate showed an attenuated rise with gabapentin (MD -9 $\mathrm{mmHg}$; $95 \% \mathrm{CI},-13$ to -5 ; low quality). At ten minutes, the analysis included 18 studies $^{21-23,26,28,30,32-39,41,43,44,47}$ with 1,244 participants where the aggregated effect estimate showed an attenuated rise with gabapentin (MD, $-8 \mathrm{mmHg}$; $95 \% \mathrm{CI},-11$ to -5 ; low quality).

There was evidence of statistical heterogeneity for all time points $\left(\mathrm{I}^{2}=82-93 \% ; P<0.001\right)$. There was no evidence of small study effects at one or ten minutes $(P=$ 0.14 and $P=0.36$, respectively). There was evidence of small study effects at five minutes $(P=0.001)$; however, the studies were missing from the left of the plot, suggesting a bias against gabapentin for this outcome. On meta-regression analysis, increasing the gabapentin dose or baseline MAP did not significantly predict gabapentin effect at any time point. Trial sequential analysis showed that gabapentin crossed the O'Brien-Fleming monitoring boundary for benefit for each time point. In addition, the required information size was reached for one, five, and ten minutes (909, 824, and 432 participants, respectively).

Heart rate Gabapentin attenuated the rise in $\mathrm{HR}$ at one minute after intubation when compared with the control group $\left(\mathrm{MD},-8\right.$ beats. $\mathrm{min}^{-1} ; 95 \% \mathrm{CI},-11$ to -5 ; moderate quality) (Fig. 4). At five minutes, the analysis included 25 studies $^{20-39,41,43-45,47}$ with 1,564 participants where the aggregated effect estimate showed an attenuated rise with gabapentin $\left(\mathrm{MD},-6\right.$ beats $\cdot \min ^{-1} ; 95 \% \mathrm{CI},-8$ to -4 ; moderate quality). At ten minutes, the analysis included 22 studies $^{20-23,25-28,30-39,41,43,44,47}$ with 1,458 participants where the aggregated effect estimate showed an attenuated rise with gabapentin (MD, -5 beats $\cdot \mathrm{min}^{-1}$; $95 \% \mathrm{CI},-7$ to -3 ; moderate quality).

There was evidence of statistical heterogeneity at all time points $\left(\mathrm{I}^{2}=46-76 \% ; P<0.01\right)$. There was evidence of small study effects at one and five minutes $(P=0.05$ and $P$ $=0.004$, respectively); however, the missing studies were to the left of the mean, suggesting a bias against gabapentin. On meta-regression analysis, an increase in the gabapentin dose predicted greater attenuation in $\mathrm{HR}$ at one minute $\left(\mathrm{R}^{2}=35 \% ; P=0.006\right)$, five minutes $\left(\mathrm{R}^{2}=38 \%\right.$; $P=0.02)$, and ten minutes $\left(\mathrm{R}^{2}=52 \% ; P=0.004\right)$. Baseline HR was not a significant predictor at any time point. Trial sequential analysis showed that gabapentin crossed the O'Brien-Fleming boundary for benefit at all time points. In addition, the results for five and ten minutes reached the required information size (1,339 and 784 participants, respectively). Nevertheless, the results for one minute failed to reach the required information size $(2,022$ participants).

Systolic blood pressure At one minute after intubation, the analysis included 15 studies $^{20,21,24,27,28,31,32,34,36,37,43-45,47,48 \quad \text { with } 928}$ participants where the aggregated effect estimate showed gabapentin attenuated the rise in SBP when compared with the control group (MD, $-16 \mathrm{mmHg} ; 95 \% \mathrm{CI},-22$ to -9 ; low quality). At five minutes, the analysis included 15 studies $^{20,21,24,27,28,30-32,34,36,37,43-45,47}$ with 921 participants where the aggregated effect estimate showed an attenuated rise with gabapentin $(\mathrm{MD},-10 \mathrm{mmHg} ; 95 \% \mathrm{CI},-16$ to -4 ; low quality). At ten minutes, the analysis included 13 studies $^{20,21,27,28,30-32,34,36,37,43,44,47}$ with 855 participants where the aggregated effect estimate showed an attenuated rise with gabapentin $(\mathrm{MD},-9 \mathrm{mmHg} ; 95 \% \mathrm{CI},-16$ to -2 ; low quality).

There was evidence of substantial statistical heterogeneity at all time points $\left(\mathrm{I}^{2}=89-94 \% ; P<\right.$ $0.001)$. There was no evidence of small study effects at 


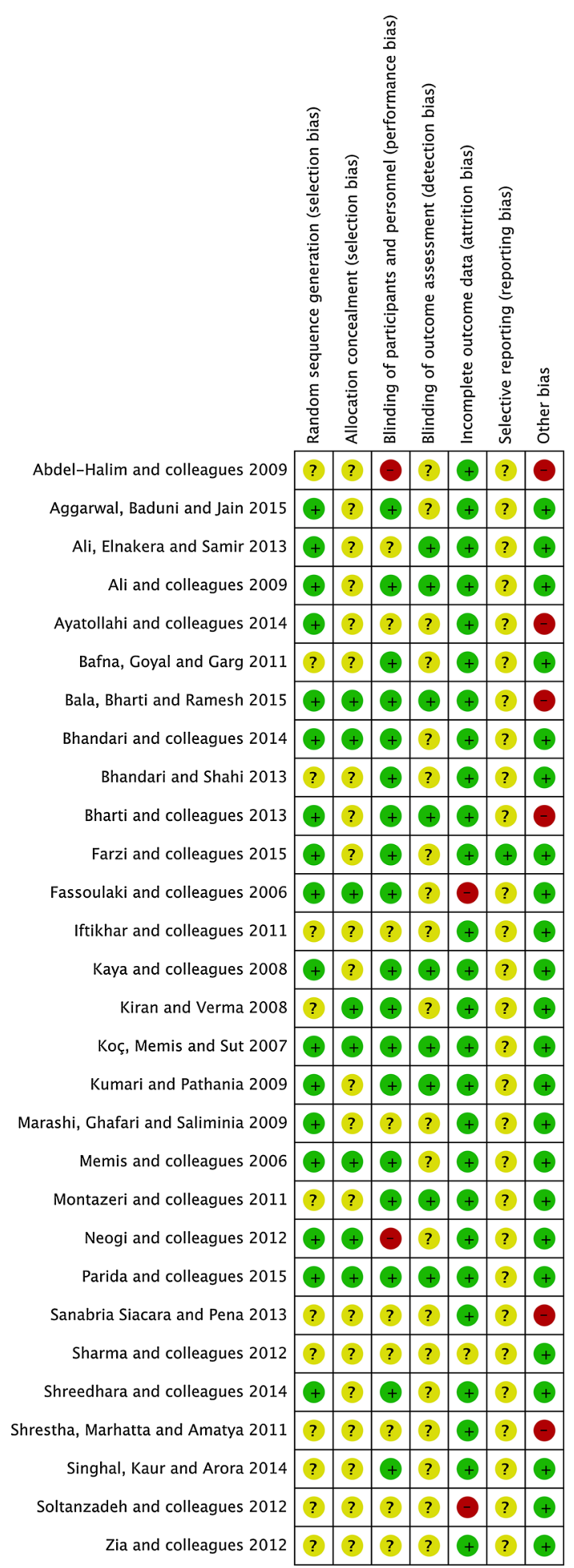

Fig. 2 Risk of bias for included studies. Green indicates low risk, yellow indicates unclear risk, and red indicates high risk

one $(P=0.27)$, five $(P=0.43)$, or ten minutes $(P=0.30)$. On meta-regression analysis, gabapentin dose and baseline SBP did not significantly predict gabapentin effect. Trial sequential analysis showed that gabapentin crossed the
O'Brien-Fleming boundary for benefit at one and five minutes. Nevertheless, the result for ten minutes did not cross the boundary for benefit. In addition, results at one, five, and ten minutes did not reach the required information size $(1,507,1,163$, and 1,654 participants, respectively).

Diastolic blood pressure At one minute after intubation, the analysis included 14 studies $^{20,21,24,27,28,31,32,34,36,37,43,44,47,48 \quad \text { with } 892}$ participants where the aggregated effect estimate showed an attenuated rise in DBP with gabapentin when compared with control (MD, $-11 \mathrm{mmHg}$; 95\% CI, -15 to -7 ; low quality). At five minutes, the analysis included 14 studies $^{20,21,24,27,28,30-32,34,36,37,43,44,47}$ with 885 participants where the aggregated effect estimate showed an attenuated rise with gabapentin ( $\mathrm{MD}-7 \mathrm{mmHg}$; $95 \% \mathrm{CI},-11$ to -4 ; low quality). At ten minutes, the analysis included 13 studies $^{20,21,27,28,30-32,34,36,37,43,44,47}$ with 855 participants where the aggregated effect estimate showed an attenuated rise with gabapentin ( $\mathrm{MD},-6 \mathrm{mmHg} ; 95 \% \mathrm{CI}-10$ to -2 ; low quality).

There was evidence of substantial statistical heterogeneity at all time points $\left(\mathrm{I}^{2}=79-89 \% ; P<\right.$ 0.001). There was no evidence of small study effects at one $(P=0.32)$, five $(P=0.24)$, or ten minutes $(P=0.30)$. On meta-regression analysis, gabapentin dose and baseline DBP did not significantly predict gabapentin effect at any time point. Trial sequential analysis showed that the results for gabapentin crossed the O'Brien-Fleming boundary for benefit for all time points. In addition, the required information size was reached for one, five, and ten minutes (647, 446, and 540 participants, respectively).

\section{Other secondary outcomes}

Eight studies ${ }^{21,22,25,26,33,35,38,41}$ reported arrhythmias as an outcome; there were no events in any of the included studies. In terms of catecholamine secretion, one study ${ }^{22}$ concluded that gabapentin resulted in lower secretion of adrenaline one minute after intubation when compared with placebo (MD, $-5 \mathrm{pg} \cdot \mathrm{mL}^{-1} ; 95 \% \mathrm{CI},-9$ to -1 ). Nevertheless, the secretion of noradrenaline $e^{22}$ was higher when compared with placebo one minute after intubation (MD, $65 \mathrm{pg} \cdot \mathrm{mL}^{-1}$; 95\% CI, 47 to 83 ).

Gabapentin use reduced the incidence of hypertension or tachycardia requiring treatment in five studies (RR, 0.15 ; 95\% CI, 0.05 to 0.48 ; moderate quality). Trial sequential analysis showed that gabapentin crossed the boundary for benefit, although it did not reach the required information size (558 participants). Definitions for this outcome were as follows; SBP $>200 \mathrm{mmHg}$ or $>30 \%$ increase from baseline for more than $60 \mathrm{sec} ;{ }^{22,38} \mathrm{HR}>130$ beats. $\mathrm{min}^{-1}$, 


\begin{tabular}{|c|c|c|c|c|c|c|c|c|c|c|c|c|}
\hline \multirow[b]{2}{*}{ Study or Subgroup } & \multicolumn{3}{|c|}{ Gabapentin } & \multicolumn{3}{|c|}{ Control } & \multicolumn{3}{|c|}{ Mean Difference } & \multirow{2}{*}{\multicolumn{2}{|c|}{$\begin{array}{c}\text { Mean Difference } \\
\text { IV, Random, } 95 \% \mathrm{CI}\end{array}$}} & \\
\hline & Mean & SD & Total & Mean & SD & Total & Weight & IV, Random, 95\% Cl & & & & \\
\hline Aggarwal, Baduni and Jain 2015 & 102 & 20 & 60 & 111 & 20 & 30 & $5.4 \%$ & $-9.00[-17.77,-0.23]$ & & $\longrightarrow$ & & \\
\hline Ali and colleagues 2009 & 92 & 3 & 25 & 110 & 12 & 25 & $6.2 \%$ & $-18.00[-22.85,-13.15]$ & & - & & \\
\hline Ayatollahi and colleagues 2014 & 89.73 & 11.57 & 15 & 108.26 & 24.91 & 15 & $4.1 \%$ & $-18.53[-32.43,-4.63]$ & & & & \\
\hline Bala, Bharti and Ramesh 2015 & 110.5 & 20 & 66 & 120 & 20 & 34 & $5.5 \%$ & $-9.50[-17.77,-1.23]$ & & $\longrightarrow$ & & \\
\hline Bhandari and colleagues 2014 & 100.3 & 10.1 & 20 & 111.15 & 10 & 20 & $5.9 \%$ & $-10.85[-17.08,-4.62]$ & & - & & \\
\hline Iftikhar and colleagues 2011 & 105 & 20 & 30 & 115 & 20 & 30 & $5.0 \%$ & $-10.00[-20.12,0.12]$ & & 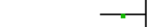 & & \\
\hline Kaya and colleagues 2008 & 82 & 18 & 30 & 92 & 16 & 30 & $5.4 \%$ & $-10.00[-18.62,-1.38]$ & & $\longrightarrow$ & & \\
\hline Kiran and Verma 2008 & 88.66 & 7.74 & 50 & 100.23 & 8.97 & 50 & $6.5 \%$ & $-11.57[-14.85,-8.29]$ & & - & & \\
\hline Koç, Memis and Sut 2007 & 104 & 20 & 20 & 126 & 20 & 20 & $4.5 \%$ & $-22.00[-34.40,-9.60]$ & & - & & \\
\hline Kumari and Pathania 2009 & 109.59 & 19.09 & 39 & 118.03 & 18.83 & 39 & $5.4 \%$ & $-8.44[-16.86,-0.02]$ & & & & \\
\hline Marashi, Ghafari and Saliminia 2009 & 91 & 15 & 25 & 115.36 & 11.4 & 25 & $5.7 \%$ & $-24.36[-31.75,-16.97]$ & & - & & \\
\hline Memis and colleagues 2006 & 91.2 & 24.9 & 60 & 108.6 & 19.8 & 29 & $5.2 \%$ & $-17.40[-26.97,-7.83]$ & & $\longrightarrow$ & & \\
\hline Montazeri and colleagues 2011 & 100 & 12 & 32 & 112 & 16 & 32 & $5.8 \%$ & $-12.00[-18.93,-5.07]$ & & $\longrightarrow$ & & \\
\hline Parida and colleagues 2015 & 95 & 7.5 & 25 & 97 & 7.5 & 25 & $6.3 \%$ & $-2.00[-6.16,2.16]$ & & & & \\
\hline Sharma and colleagues 2012 & 88.77 & 4.72 & 30 & 118.83 & 9.09 & 30 & $6.4 \%$ & $-30.06[-33.73,-26.39]$ & & $=$ & & \\
\hline Shreedhara and colleagues 2014 & 104 & 20 & 30 & 104 & 20 & 30 & $5.0 \%$ & $0.00[-10.12,10.12]$ & & & & \\
\hline Shrestha, Marhatta and Amatya 2011 & 95.2 & 11.76 & 18 & 101.98 & 14.69 & 18 & $5.4 \%$ & $-6.78[-15.47,1.91]$ & & & & \\
\hline Soltanzadeh and colleagues 2012 & 90.23 & 7.8 & 40 & 95.3 & 12.4 & 50 & $6.3 \%$ & $-5.07[-9.27,-0.87]$ & & & & \\
\hline Total $(95 \% \mathrm{Cl})$ & & & 615 & & & 532 & $100.0 \%$ & $-12.48[-16.99,-7.96]$ & & & & \\
\hline \multicolumn{9}{|c|}{$\begin{array}{l}\text { Heterogeneity: } \text { Tau }^{2}=79.03 ; \mathrm{Chi}^{2}=153.35, \mathrm{df}=17(\mathrm{P}<0.00001) ; \mathrm{I}^{2}=89 \% \\
\text { Test for overall effect: } Z=5.42(P<0.00001)\end{array}$} & $\frac{1}{-100}$ & -50 & 50 & 100 \\
\hline & & & & & & & & & & s gabapentir & n Favours & \\
\hline
\end{tabular}

Fig. 3 Forest plot of gabapentin effects on mean arterial pressure at one minute

SBP $>200 \mathrm{mmHg}$ or $>30 \%$ increase from baseline for more than $60 \mathrm{sec} ;{ }^{26}$ MAP or HR $>20 \%$ of baseline $;{ }^{29}$ MAP $>110$ mmHg. ${ }^{40}$

One study ${ }^{26}$ conducted in hypertensive patients reported any incidences of hypotension requiring treatment $(\mathrm{SBP}<$ $90 \mathrm{mmHg}$ or $>30 \%$ from baseline lasting more than 60 sec); there were no significant differences between the groups (RR, 2.40; 95\% CI, 0.74 to 7.79 ). One study ${ }^{31}$ reported any incidence of bradycardia requiring treatment $\left(\mathrm{HR}<40\right.$ beats $\left.\cdot \mathrm{min}^{-1}\right)$. There was no significant difference in bradycardia with gabapentin (RR, 3.00; $95 \% \mathrm{CI}, 0.13$ to 69.87).
Gabapentin vs fentanyl, clonidine, or beta blockers

When compared with clonidine, the only significant difference in hemodynamic variables was a higher HR at ten minutes in the gabapentin group when compared with the clonidine group ${ }^{37,39,42-44}$ (MD, 5 beats $\mathrm{min}^{-1} ; 95 \% \mathrm{CI}$, 3 to 7 ; moderate quality). One study $^{45}$ compared gabapentin with a beta blocker (esmolol). The only difference in hemodynamic variables was a higher HR at one minute in the gabapentin group when compared with the esmolol group (MD, 13 beats. $\min ^{-1} ; 95 \% \mathrm{CI}, 4$ to 21 ). The incidence of bradycardia was not significantly

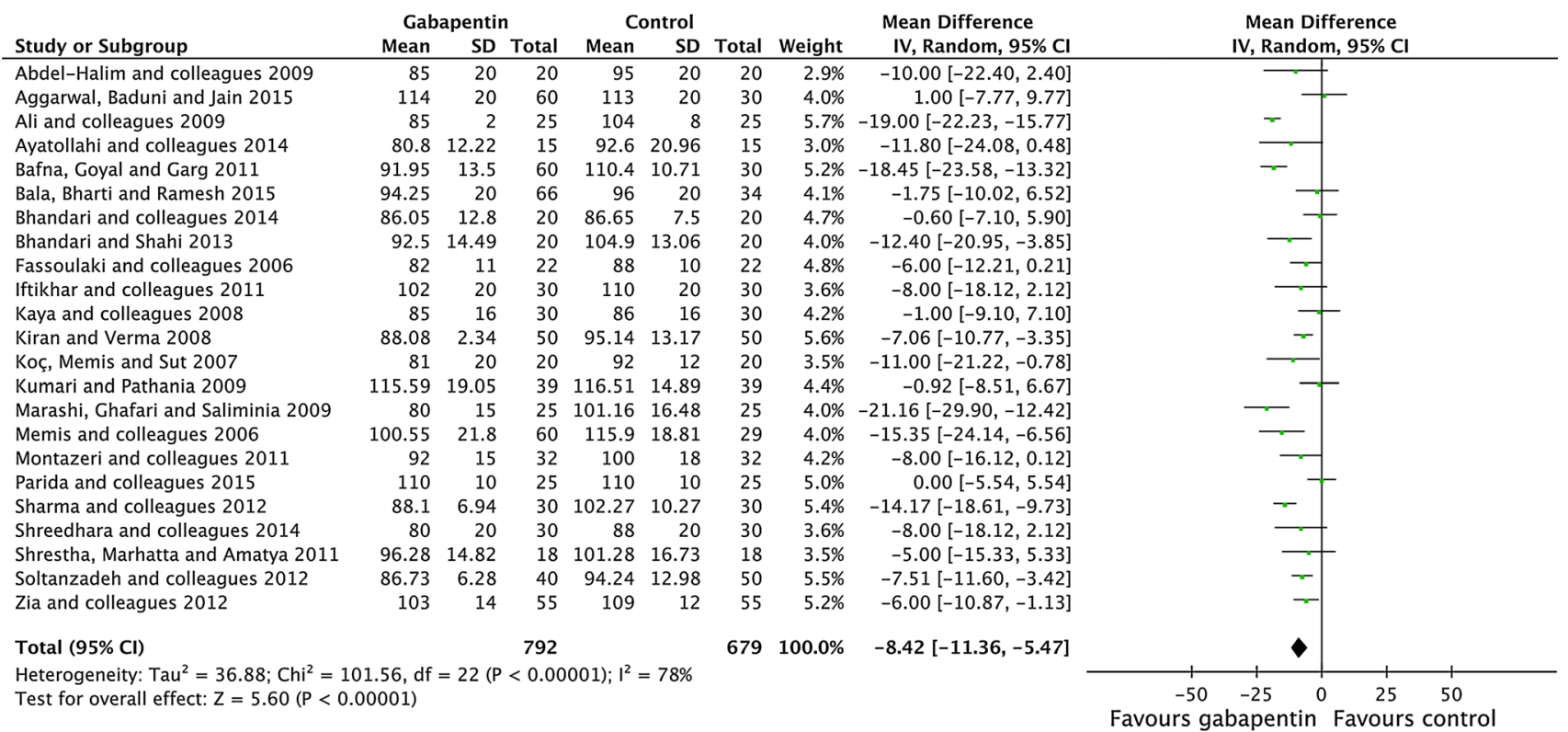

Fig. 4 Forest plot of gabapentin effects on heart rate at one minute 
different when gabapentin was compared with clonidine (RR, 0.49; 95\% CI, 0.07 to 3.60) or esmolol (RR, 0.33; $95 \% \mathrm{CI}, 0.01$ to 7.68$)$.

One study compared gabapentin with intravenous fentanyl. ${ }^{41}$ Intravenous fentanyl resulted in greater attenuation of $\mathrm{HR}$ at one (MD, 14 beats. $\min ^{-1}$; $95 \% \mathrm{CI}$, 8 to 20 ), five (MD, 12 beats. $\min ^{-1} ; 95 \% \mathrm{CI}, 7$ to 17 ), and ten minutes (MD, 10 beats $\min ^{-1} ; 95 \% \mathrm{CI}, 5$ to 15 ). Furthermore, intravenous fentanyl resulted in greater attenuation of MAP at one minute (MD, $13 \mathrm{mmHg} ; 95 \%$ CI, 8 to 18$)$.

\section{Sensitivity analysis}

Only two of the included studies were at low risk of bias, ${ }^{35,41}$ which resulted in no significant reductions for many outcomes. Excluding studies with estimated standard deviations did not significantly affect results. "RemoveOne" sensitivity analysis showed that there were no influential studies in any of the analyses.

\section{Discussion}

There are several limitations with the results of this review. We were unable to provide any results for the primary outcomes because the inclusion of low-risk patients resulted in either zero incidences of these events or lack of reporting of these outcomes within the included studies. Secondly, as previously discussed, there is limited evidence with regard to clinically important adverse events such as hypotension and bradycardia. Many studies were at potential risk of bias, particularly for allocation concealment, which may bias the results from this review. ${ }^{49}$ Indeed, only two studies ${ }^{35,41}$ included in the review were deemed to be at low risk of bias for most domains, which limited the quality of the evidence. ${ }^{14}$ In addition to these issues with internal validity, many of the studies included in the review were conducted in the Middle East and Asia, and therefore, the applicability of our results to North American and European populations is unclear.

With regard to outcome measurements, very few of the included studies provided details of the equipment used to obtain noninvasive blood pressure measurements. As values from oscillometric methods are algorithmically derived, these may vary between devices, which may introduce heterogeneity into our results. Also, this lack of information meant that it was problematic to evaluate whether such devices are valid, precise, and accurate. As the majority of the included studies measured blood pressure at discrete time points, important hypotensive or hypertensive episodes may have been missed, as such discrete measurements may not reflect the average values occurring between such measurements. Finally, it is unclear how gabapentin compares with other standard agents such as lidocaine. Importantly, when gabapentin was directly compared with a standard agent such as intravenous fentanyl, gabapentin was inferior for many hemodynamic outcomes.

Despite the limitations of the review, we found that gabapentin resulted in significant attenuation of mean arterial blood pressure, HR, SBP, and DBP when compared with control (moderate- to low-quality evidence). Most of these results crossed the monitoring boundaries for benefit and reached the required information sizes for a definitive answer on trial sequential analysis, reducing type I and II errors in our analysis. In addition, gabapentin resulted in a significant reduction in the proportion of patients requiring treatment for hypertension or tachycardia. Following intubation, one study found that gabapentin reduced circulating levels of adrenaline and increased noradrenaline. Although data were limited, gabapentin appears comparable with clonidine and beta blockers in terms of its hemodynamic effects following intubation. Increases in gabapentin dosages were associated with greater attenuation of HR responses on meta-regression analysis. Although many of these outcomes reached our predefined clinical thresholds, caution is advised as these were not empirically derived.

The hemodynamic response to intubation involves a stress response, which leads to increases in catecholamine levels and subsequent increases in HR and blood pressure ${ }^{50}$ In high-risk patients, such increases can lead to myocardial ischemia and therefore myocardial infarction. ${ }^{1,51,52}$ Many agents have been used to attenuate the hemodynamic response to intubation and thus aim to reduce myocardial ischemia. ${ }^{2}$ Although agents such as clonidine ${ }^{53}$ and beta blockers have shown promise in reducing perioperative cardiac events, the large randomized-controlled POISE studies showed an increase in mortality and stroke with perioperative beta blocker therapy ${ }^{4}$ and increases in clinically important hypotension and non-fatal cardiac arrest with clonidine. ${ }^{6}$ Therefore, the search continues for effective agents that can reduce perioperative myocardial events in high-risk patients without increasing such adverse events as hypotension and bradycardia and therefore all-cause mortality. Although such perioperative events as intubation, extubation, surgery, and pain can contribute to increasing myocardial demand, ${ }^{3}$ our review focused only on the brief hemodynamic response following intubation. Therefore, we advise caution in extrapolating these results with any direct link with longer-term adverse cardiac events in the perioperative period, such as those studied in POISE. Despite this limitation, gabapentin is 
known to reduce postoperative pain, ${ }^{8}$ attenuate the hemodynamic response to intubation, and reduce catecholamine and cortisol responses postoperatively; ${ }^{54}$ therefore, longer-term effects on reducing myocardial demand cannot be ruled out.

Gabapentin has proven efficacy as a perioperative analgesic with reductions in pain scores and lower opioid consumption in various types of surgery. ${ }^{8}$ Other beneficial effects include reductions in preoperative anxiety, vomiting, and pruritus, with some evidence of reductions in chronic post-surgical pain at the expense of increased sedation. $^{8,55}$ Interestingly, these trials provide the only evidence of the effects of gabapentin in high-risk patients. Within these postoperative pain trials, the results of studies with cardiothoracic surgery patients ${ }^{8,56-58}$ (which included high-risk cardiac patients) suggest a reduction in postoperative arrhythmia with the use of gabapentin (RR, 0.55 ; $95 \%$ CI, 0.28 to 1.08$)$.

Our review suggests that gabapentin may also be an effective agent for attenuation of the hemodynamic response to intubation. We found only one study suggesting that this might be mediated by reductions in adrenaline when compared with control. ${ }^{22}$ Previous in vitro research has suggested that gabapentin may inhibit the release of catecholamines from adrenal chromaffin cells, ${ }^{59}$ which may confirm this as a possible mechanism of action. Furthermore, a recent randomized-controlled trial has shown that preoperative gabapentin can reduce postoperative catecholamine (both adrenaline and noradrenaline) and cortisol concentrations in women undergoing hysterectomy. ${ }^{54}$ Nevertheless, the magnitude of difference in adrenaline between the groups in our review was around $8 \%$, which may be regarded as clinically small. Another potential mechanism may relate to calcium channel inhibition. As calcium channel blockers can attenuate the hemodynamic response and share a target mechanism with gabapentin, this may produce similar effects in a clinical population. ${ }^{60}$

Our meta-regression analysis found that a gabapentin dose was associated with greater attenuation of $\mathrm{HR}$, with higher doses producing lower HRs when compared with control. A previous meta-regression has shown a similar effect when evaluating lower morphine consumption during the postoperative period. ${ }^{8}$ These meta-regression results suggest that future studies should aim to use higher doses in order to improve the absolute effects of gabapentin on HR responses. Nevertheless, the oral route of gabapentin used in the included studies has implications for its use in high-risk patients, which may be prohibitive in emergency surgery. In addition, it is unclear whether titration of the gabapentin dosage would alter efficacy, an issue raised in the first POISE study. ${ }^{4}$ Moreover, it is unclear whether such increases in dose would affect the incidence of bradycardia and hypotension, which may have been responsible for the increased mortality in POISE. With regard to the pharmacokinetics of gabapentin, bioavailability is known to decrease with increasing dosages, therefore plasma concentrations may not reflect the dose administered. ${ }^{61}$ Baseline hemodynamic variables recorded before induction were not associated with greater attenuation of hemodynamic variables on meta-regression analysis. This suggests that similar differences would be achieved regardless of the baseline blood pressure or HR of the participants. Despite this, it should be emphasized that most of the included studies comprised low-risk nonhypertensive patients, and therefore, the range of baseline values was limited. Furthermore, our meta-regression analysis may be underpowered to detect associations for these outcomes.

Gabapentin was found to reduce the risk of hypertension or tachycardia requiring treatment. This result is intuitive given the observed effects of gabapentin on HR and blood pressure. Nevertheless, data from the studies included in this review are limited with regard to episodes of bradycardia or hypotension. Indeed, one study in the review excluded three patients from the analysis due to hypotension, ${ }^{47}$ and one study excluded a patient due to an episode of bradycardia. ${ }^{31}$ The former study was not included in the meta-analysis as it did not report whether these patients required treatment. As intraoperative hypotension may be associated with stroke, ${ }^{62}$ myocardial injury, acute kidney injury, ${ }^{63}$ and mortality, ${ }^{64}$ future studies with gabapentin should aim to report these outcomes. These studies should be well designed (with full intention-to-treat analysis) and adequately powered to detect differences in these clinically important outcomes and avoid reporting surrogate outcomes such as hemodynamic measurements. For example, we calculated a required information size of 558 participants to provide a definitive answer for our outcome of hypertension or tachycardia (requiring treatment).

As previously stated, future research should aim to report the incidences of adverse events associated with the use of gabapentin in the perioperative period, particularly as these may be associated with perioperative mortality. This would have implications for the use of gabapentin for attenuating the hemodynamic response to intubation as well as for using it more widely in postoperative pain control. Clinical trials should aim to address issues with internal validity, such as the use of identical placebo controls, intention-to-treat analysis of participants suffering adverse events, and adequate allocation concealment. Ultimately, adequately powered randomized-controlled trials should examine the effects of gabapentin in highrisk patients (such as those with previous myocardial infarction or ischemic heart disease) and determine effects on clinically relevant outcomes, such as mortality, 
myocardial infarction, arrhythmia and myocardial ischemia, while avoiding reporting surrogate variables as primary outcomes.

In conclusion, it remains unknown whether gabapentin improves clinically relevant outcomes such as death and myocardial infarction since studies failed to report on these. Nevertheless, this review has found evidence that gabapentin reduces HR and blood pressure responses to intubation. Even so, caution is advised with these results as there are few data from trials with a low risk of bias that focus on adverse hemodynamic events in high-risk patients. This novel meta-analysis shows the beneficial effects of gabapentin in attenuating the hemodynamic response to intubation.

Funding None.

Conflicts of interest None declared.

Author contributions Brett Doleman developed the concept for this review and wrote the manuscript. Matthew Sherwin, Jonathan N. Lund, and John P. Williams participated in editing the manuscript. All authors contributed to the data analysis.

Editorial responsibility This submission was handled by Dr. Philip M. Jones, Associate Editor, Canadian Journal of Anesthesia.

\section{Appendix: MEDLINE search}

1. gabapentin.ti,ab

2. neurontin.ti,ab

3. 1 OR 2

4. intubation.ti,ab

5. exp INTUBATION, INTRATRACHEAL/

6. 4 OR 5

7. 3 AND 6

\section{References}

1. Kovac AL. Controlling the hemodynamic response to laryngoscopy and endotracheal intubation. J Clin Anesth 1996; 8: 63-79.

2. Khan FA, Ullah $H$. Pharmacological agents for preventing morbidity associated with the haemodynamic response to tracheal intubation. Cochrane Database Syst Rev 2013; 7: CD004087.

3. Devereaux PJ, Goldman L, Cook DJ, Gilbert K, Leslie K, Guyatt $G H$. Perioperative cardiac events in patients undergoing noncardiac surgery: a review of the magnitude of the problem, the pathophysiology of the events and methods to estimate and communicate risk. CMAJ 2005; 173: 627-34.

4. POISE Study Group; Devereaux PJ, Yang H, Yusuf S, et al. Effects of extended-release metoprolol succinate in patients undergoing non-cardiac surgery (POISE trial): a randomised controlled trial. Lancet 2008; 371: 1839-47.
5. Wallace AW, Galindez D, Salahieh A, et al. Effect of clonidine on cardiovascular morbidity and mortality after noncardiac surgery. Anesthesiology 2004; 101: 284-93.

6. Devereaux PJ, Sessler DI, Leslie K, et al. Clonidine in patients undergoing noncardiac surgery. N Engl J Med 2014; 370: 150413.

7. Achuthan S, Singh I, Varthya SB, Srinivasan A, Chakrabarti A, Hota $D$. Gabapentin prophylaxis for postoperative nausea and vomiting in abdominal surgeries: a quantitative analysis of evidence from randomized controlled clinical trials. Br J Anaesth 2015; 114: 588-97.

8. Doleman B, Heinink TP, Read DJ, Faleiro RJ, Lund JN, Williams $J P$. A systematic review and meta-regression analysis of prophylactic gabapentin for postoperative pain. Anaesthesia 2015; 70: 1186-204.

9. Kong $V K$, Irwin $M G$. Gabapentin: a multimodal perioperative drug? Br J Anaesth 2007; 99: 775-86.

10. Sear JW, Higham H, Foex P. Beta-blockade and other perioperative pharmacological protectors: what is now available and efficacious? Br J Anaesth 2015; 115: 333-6.

11. Moher D, Liberati A, Tetzlaff J, Altman DG, PRISMA Group. Preferred reporting items for systematic reviews and metaanalyses: the PRISMA statement. Ann Intern Med 2009; 151: 264-9.

12. Higgins JP, Altman DG, Gotzsche PC, et al. The Cochrane Collaboration's tool for assessing risk of bias in randomised trials. BMJ 2011; 343: d5928.

13. Higgins JP, Deeks JJ, Altman DG. Special topics in statistics. In: Higgins JP, Green S, editors. Cochrane Handbook for Systematic Reviews of Interventions: Cochrane Book Series. Chichester: John Wiley and Sons Ltd; 2008. p. 481-529.

14. Guyatt GH, Oxman AD, Kunz R, et al. What is "quality of evidence" and why is it important to clinicians? BMJ 2008; 336 : 995-8.

15. Egger M, Davey Smith $G$, Schneider M, Minder $C$. Bias in metaanalysis detected by a simple, graphical test. BMJ 1997; 315: 629-34.

16. Thompson SG, Higgins JP. How should meta-regression analyses be undertaken and interpreted? Stat Med 2002; 21: 1559-73.

17. Imberger G, Gluud C, Boylan J, Wetterslev J. Systematic reviews of anesthesiologic interventions reported as statistically significant: problems with power, precision, and type 1 error protection. Anesth Analg 2015; 121: 1611-22.

18. Review Manager (RevMan). Computer program, Version 5.3. Copenhagen: The Nordic Cochrane Centre, The Cochrane Collaboration; 2014. Available from URL: http://tech.cochrane. org/revman/about-revman-5 (accessed April 2016).

19. Comprehensive Meta-analysis Version 3. Englewood, New Jersey: Biostat, 2015. Available from URL: https://www.metaanalysis.com/ (accessed April 2016).

20. Abdel-Halim JM, ElAwady GA, ElShaikh SM, Azer MS. Gabapentin and dexamethasone as adjuvants for intraoperative and postoperative pain management. Egypt J Anaesth 2009; 25: 357-64.

21. Aggarwal S, Baduni N, Jain A. Attenuation of pressor response to laryngoscopy and intubation-a comparative study between two doses of gabapentin in patients undergoing laparoscopic cholecystectomy. Anaesth Pain Intensive Care 2015; 19: 33-6.

22. Ali AR, El Gohary M, Ashmawi HS, El-Kerdawy HM, Essa HH. Efficacy of preoperative oral gabapentin in attenuation of neuroendocrine response to laryngoscopy and endotracheal intubation. J Med Sci 2009; 9: 24-9.

23. Ali AA, Elnakera AM, Samir A. Effect of two different doses of gabapentin on the intraocular pressure and hemodynamic stress responses to laryngoscopy and tracheal intubation. ISRN Anesthesiology 2013. DOI:10.1155/2013/698205. 
24. Ayatollahi $V$, Mirshamsi $P$, Behdad $S$, Amirdosara $M$, Vaziribozorg $S$. Effect of oral gabapentin on haemodynamic variables during microlaryngoscopic surgery. Anaesthesiol Intensive Ther 2014; 46: 17-22.

25. Bafna U, Goyal VK, Garg A. A comparison of different doses of gabapentin to attenuate the haemodynamic response to laryngoscopy and tracheal intubation in normotensive patients. J Anaesthesiol Clin Pharmacol 2011; 27: 43-6.

26. Bala I, Bharti N, Ramesh NP. Effect of gabapentin pretreatment on the hemodynamic response to laryngoscopy and tracheal intubation in treated hypertensive patients. Acta Anaesthesiol Taiwan 2015; 53: 95-8.

27. Bhandari $G$, Shahi $K S$. Effect of gabapentin on pressor response to laryngoscopy and tracheal intubation: a double blind randomized placebo controlled study. People's Journal of Scientific Research 2013; 6: 1-6.

28. Bhandari V, Dhasmana DC, Dureja S, Sachan PK, Chaturvedi A. Gabapentin pre-treatment for pressor response to direct laryngoscopy and tracheal intubation: a randomized, doubleblind, placebo controlled study. Int J Basic Clin Pharmacol 2014; 3: 800-3.

29. Bharti N, Bala I, Narayan $V$, Singh $G$. Effect of gabapentin pretreatment on propofol consumption, hemodynamic variables, and postoperative pain relief in breast cancer surgery. Acta Anaesthesiol Taiwan 2013; 51: 10-3.

30. Farzi $F$, Haddadi $S$, Ebrahimpour $N$, et al. A survey on the effect of oral gabapentin on hemodynamic changes during direct laryngoscopy and tracheal intubation and intraoperative bleeding in patients undergoing septorhinoplasty. Anesth Pain Med 2015. DOI:10.5812/aapm.29705.

31. Fassoulaki A, Melemeni A, Paraskeva A, Petropoulos G. Gabapentin attenuates the pressor response to direct laryngoscopy and tracheal intubation. Br J Anaesth 2006; 96: 769-73.

32. Iftikhar T, Taqi A, Sibtain A, Anjum S, Awan I. Oral gabapentin reduces hemodynamic response to direct laryngoscopy and tracheal intubation. Anaesth Pain Intensive Care 2011; 15: 17-20.

33. Kaya FN, Yavascaoglu B, Baykara M, Altun GT, Gulhan N, Ata $F$. Effect of oral gabapentin on the intraocular pressure and haemodynamic responses induced by tracheal intubation. Acta Anaesthesiol Scand 2008; 52: 1076-80.

34. Kiran S, Verma D. Evaluation of gabapentin in attenuating pressor response to direct laryngoscopy and tracheal intubation. SAJAA 2008; 14: 43-6.

35. Koç S, Memis D, Sut N. The preoperative use of gabapentin, dexamethasone, and their combination in varicocele surgery: a randomized controlled trial. Anesth Analg 2007; 105: 1137-42.

36. Kumari I, Pathania VS. A prospective randomised double-blind placebo controlled trial of oral gabapentin in attenuation of haemodynamic responses during laryngoscopy and tracheal intubation. J Anaesthesiol Clin Pharmacol 2009; 25: 439-43.

37. Marashi SM, Ghafari MH, Saliminia A. Attenuation of hemodynamic responses following laryngoscopy and tracheal intubation-comparative assessment of clonidine and gabapentin premedication. Middle East J Anaesthesiol 2009; 20: 233-7.

38. Memis D, Turan A, Karamanlioglu B, Seker S, Ture M. Gabapentin reduces cardiovascular responses to laryngoscopy and tracheal intubation. Eur J Anaesthesiol 2006; 23: 686-90.

39. Montazeri K, Kashefi P, Honarmand A, Safavi M, Hirmanpour A. Attenuation of the pressor response to direct laryngoscopy and tracheal intubation: oral clonidine vs. oral gabapentin premedication. J Res Med Sci 2011; 16: S377-86.

40. Neogi M, Basak S, Ghosh D, Mukherjee S, Dawn S, Bhattacharjee DP. A randomized double-blind placebocontrolled clinical study on the effects of gabapentin premedication on hemodynamic stability during laparoscopic cholecystectomy. J Anaesthesiol Clin Pharmacol 2012; 28: 456-9.
41. Parida S, Ashraf NC, Mathew JS, Mishra SK, Badhe AS. Attenuation of the haemodynamic responses to tracheal intubation with gabapentin, fentanyl and a combination of both: a randomised controlled trial. Indian J Anaesth 2015; 59: 306-11.

42. Sanabria Siacara HE, Pena Valencia $F$. Eficacia de la premedicación con clonidina comparado con gabapentina vía oral para reducir la respuesta simpática a la laringoscopia e intubación traqueal en el Hospital Central Cruz Roja Mexicana Polanco-2013. Available from: http://ri.uaemex.mx/handle/ 123456789/13824 (accessed April 2016).

43. Sharma S, Angral $R$, Jamwal A, Bhanotra K. Comparative evaluation of gabapentin, clonidine and combination of both the drugs to attenuate the pressor response to direct laryngoscopy and intubation. The Internet Journal of Anesthesiology 2012; 30: number 4.

44. Shekharappa NS, Singh NR, Singh HS, Singh LC, Singh TH. A comparative study of clonidine and gabapentin for attenuating hemodynamic responses to laryngoscopy and tracheal intubation. J Med Soc 2014; 28: 94-8.

45. Shrestha GS, Marhatta MN, Amatya R. Use of gabapentin, esmolol or their combination to attenuate haemodynamic response to laryngoscopy and intubation. Kathmandu Univ Med J (KUMJ) 2011; 9: 238-43.

46. Singhal SK, Kaur K, Arora P. Oral clonidine versus gabapentin as premedicant for obtunding hemodynamic response to laryngoscopy and tracheal intubation. Saudi J Anaesth 2014; 8: 172-7.

47. Soltanzadeh $M$, Soltani $F$, Mohtadi A, et al. Effects of preoperative oral gabapentin in reduction of intraocular pressure and cardiovascular changes following laryngoscopy and tracheal intubation. Life Science Journal 2012; 3: 9.

48. Zia MA, Niazi SK, Ashraf R, Gilani TU. Effect of preoperative gabapentin on haemodynamic response to laryngoscopy and tracheal intubation in patients undergoing any elective surgery. Pakistan J Med Health Sci 2012; 6: 1003-5.

49. Schulz KF, Grimes DA. Allocation concealment in randomised trials: defending against deciphering. Lancet 2002; 359: 614-8.

50. Derbyshire DR, Chmielewski A, Fell D, Vater M, Achola K, Smith $G$. Plasma catecholamine responses to tracheal intubation. Br J Anaesth 1983; 55: 855-60.

51. Slogoff $S$, Keats $A S$. Does perioperative myocardial ischemia lead to postoperative myocardial infarction? Anesthesiology 1985; 62: 107-14.

52. Roy WL, Edelist G, Gilbert B. Myocardial ischemia during noncardiac surgical procedures in patients with coronary-artery disease. Anesthesiology 1979; 51: 393-7.

53. Wijeysundera DN, Naik JS, Beattie WS. Alpha-2 adrenergic agonists to prevent perioperative cardiovascular complications: a meta-analysis. Am J Med 2003; 114: 742-52.

54. Karbic VO, Skoda M, Antoncic D, Kristofic I, Komar D, Trobonjaca Z. Gabapentin-induced changes of plasma cortisol level and immune status in hysterectomized women. Int Immunopharmacol 2014; 23: 530-6.

55. Clarke H, Bonin RP, Orser BA, Englesakis M, Wijeysundera DN, $K a t z J$. The prevention of chronic postsurgical pain using gabapentin and pregabalin: a combined systematic review and meta-analysis. Anesth Analg 2012; 115: 428-42.

56. Grosen K, Drewes AM, Hojsgaard A, Pfeiffer-Jensen M, Hjortdal $E$, Pilegaard $H K$. Perioperative gabapentin for the prevention of persistent pain after thoracotomy: a randomized controlled trial. Eur J Cardiothorac Surg 2014; 46: 76-85.

57. Rapchuk IL, O'Connell L, Liessmann CD, Cornelissen HR, Fraser $J F$. Effect of gabapentin on pain after cardiac surgery: a randomised, double-blind, placebo-controlled trial. Anaesth Intensive Care 2010; 38: 445-51.

58. Ucak A, Onan B, Sen H, Selcuk I, Turan A, Yilmaz AT. The effects of gabapentin on acute and chronic postoperative pain 
after coronary artery bypass graft surgery. J Cardiothorac Vasc Anesth 2011; 25: 824-9.

59. Todd RD, McDavid SM, Brindley RL, Jewell ML, Currie KP. Gabapentin inhibits catecholamine release from adrenal chromaffin cells. Anesthesiology 2012; 116: 1013-24.

60. Cheng JK, Chiou LC. Mechanisms of the antinociceptive action of gabapentin. J1 Pharmacol Sci 2006; 100: 471-86.

61. Stewart BH, Kugler AR, Thompson PR, Bockbrader HN. A saturable transport mechanism in the intestinal absorption of gabapentin is the underlying cause of the lack of proportionality between increasing dose and drug levels in plasma. Pharm Res 1993; 10: 276-81.
62. $N g J L$, Chan MT, Gelb AW. Perioperative stroke in noncardiac, nonneurosurgical surgery. Anesthesiology 2011; 115: 879-90.

63. Walsh M, Devereaux PJ, Garg AX, et al. Relationship between intraoperative mean arterial pressure and clinical outcomes after noncardiac surgery: toward an empirical definition of hypotension. Anesthesiology 2013; 119: 507-15.

64. Bijker JB, van Klei WA, Vergouwe $Y$, et al. Intraoperative hypotension and 1-year mortality after noncardiac surgery. Anesthesiology 2009; 111: 1217-26. 